\title{
Airfoil to Improve Aerodynamic Performance OF Aileron Reduced Spanwise in Combat Helicopter
}

\author{
Giovanni Maria De Pratti* \\ "La Sapienza" University of Rome, DIMA
}

\begin{abstract}
Combat helicopters frequently operate in the part of Planetary Boundary Layer (PBL) characterised by the presence of dust and many other aggressive agents, particularly, in desertic areas and in marine sites, so the aerodynamic performance of their ailerons reduced spanwise, carrying out weapon

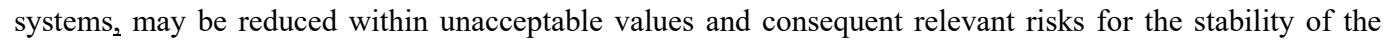
copter. According to some experts, ailerons for weapon systems of helicopter are not involved in the global lift of the copter, but their operative function is only to carry the combat systems..Nevertheless, some crash occurred to US combat helicopters suggest a different point of view, and an aileron damage, perhaps due to a kind of dynamic stall phenomenon, seems have been caused the copter fall. These problems may be avoided using particularly airfoil for the section of aileron instead of classic ones as NACA four digit series (as 00120018). These profiles may be FFA-W1-XXX series, characterised by a double curvature of camber-line.

In the present paper, after a deep analysis of operative conditions of modern combat helicopters, the aerodynamic performance of aileron section as NACA 0018 and FFA-W1-182 have been analysed and compared, and the results of tests carried out on a water table test bench are exposed and discusses.
\end{abstract}

\section{Introduction}

At the present time many types of combat helicopters exist as those showed in Figs. 1 and 2.

\footnotetext{
*Contact Author: giovannimaria.depratti@uniroma1.it
} 


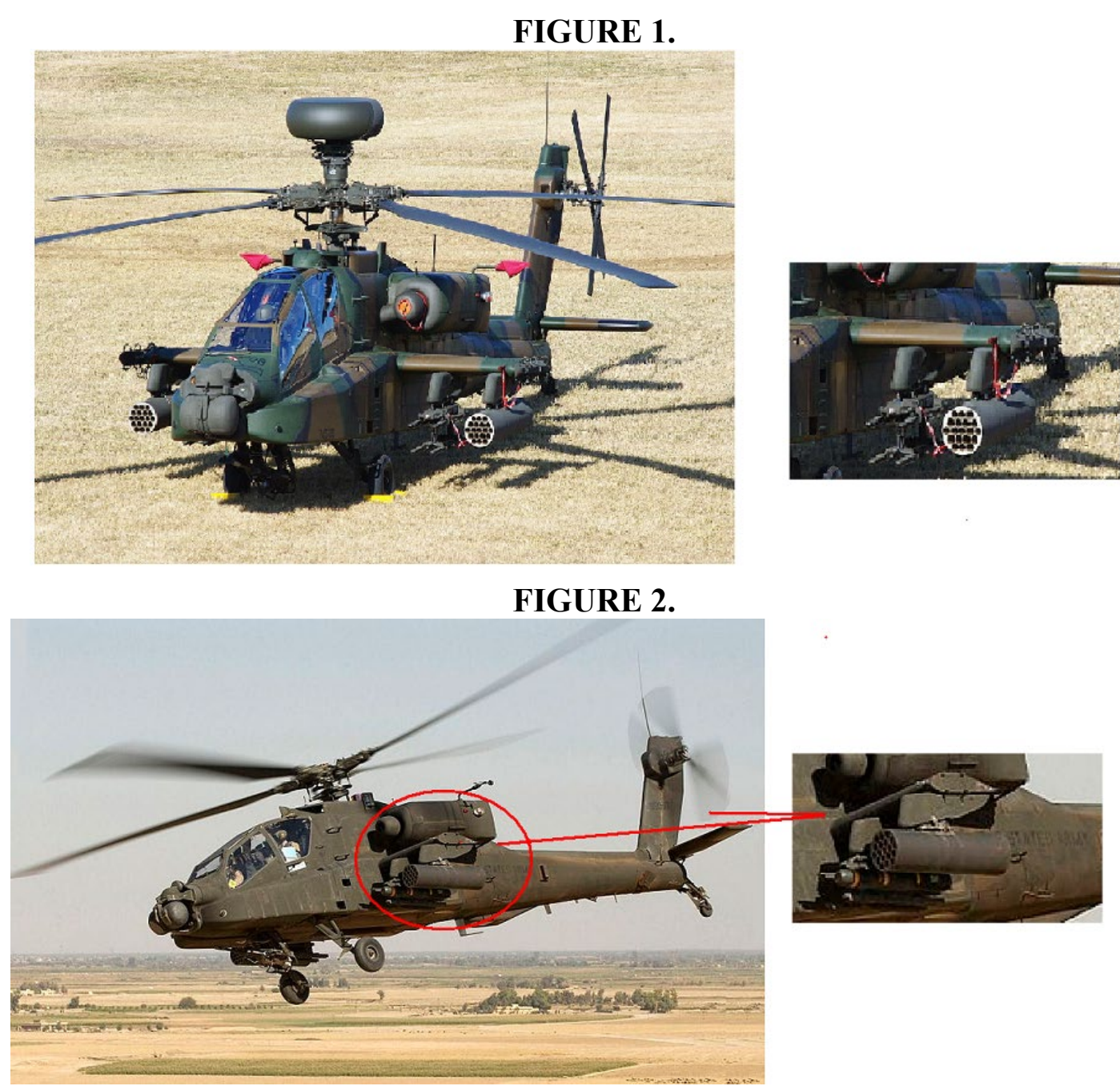

In the same Figs. we can see also the particular aspect of aileron with weaponry. In the Fig. 3 the aileron with wartime loads is shown. In literature, we can find some very interesting examples of reports about helicopter failures, as in [2] or in some databases as [16]. Also vibrations and fatigue may be main causes of copter crashes [15]. According to a number of experts, the above mentioned ailerons would not have any lift contribution, nevertheless a contribution could exist as shown by the Fig. 4 that shows an incident occurred to a combat helicopter as consequence of a fault occurred to right aileron during a simulated combat action. In operative running conditions, lift instability or lift rapid decrease may be very hazardous. According a study on about 1980-1985 ([11]) many scout or attack helicopters have experimented accidents due to tail rotor failures, nevertheless, after the introduction of lateral ailerons, the doubt of accidents due to them exists. Some papers about helicopters with compound configuration report about many aspects related to the contribution of ailerons to the copter global lift [17].

The present papare analyses the contribution of aileron reduced spanwise to global lift as in compound helicopter configuration [17]. Under another poit of view, the present paper contributes to a deep knowledge of airfoil beahviour as isolated one or in cascade as in turbomachinery. 

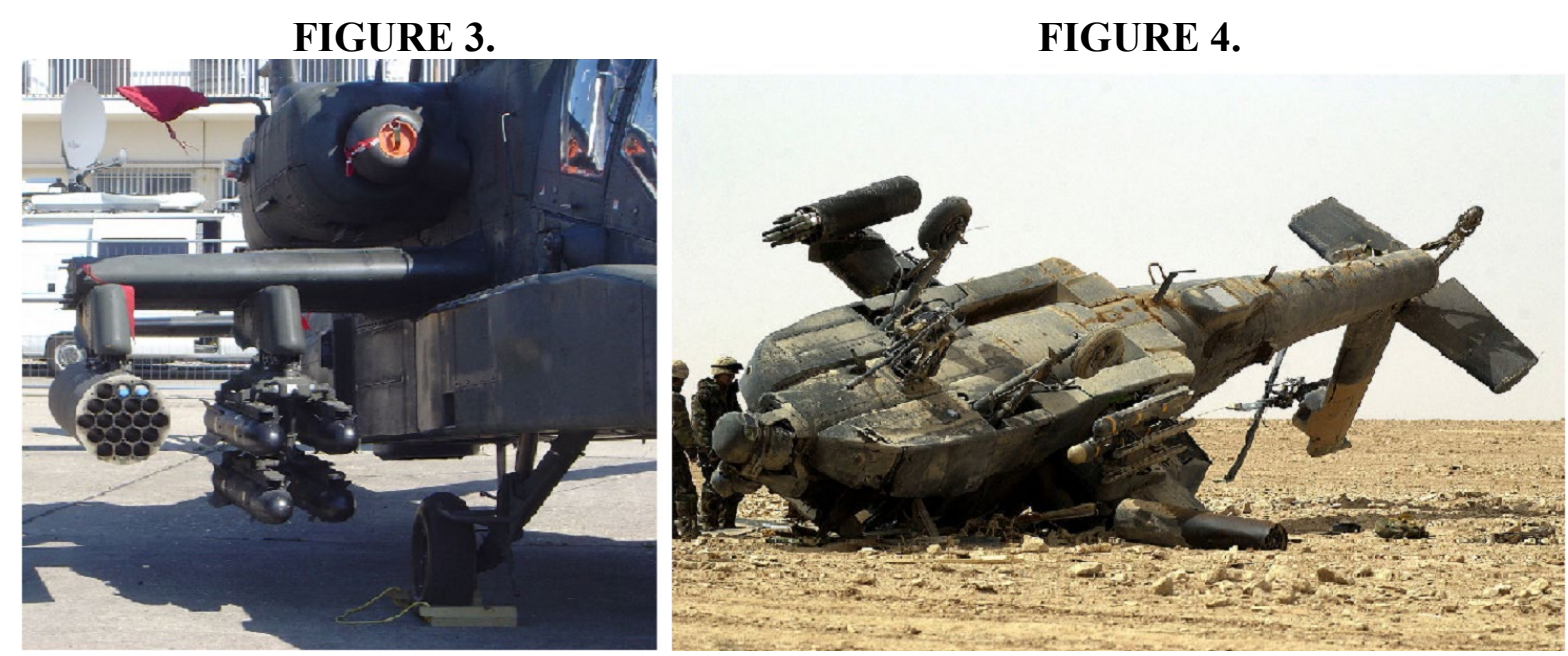

FIGURE 5.

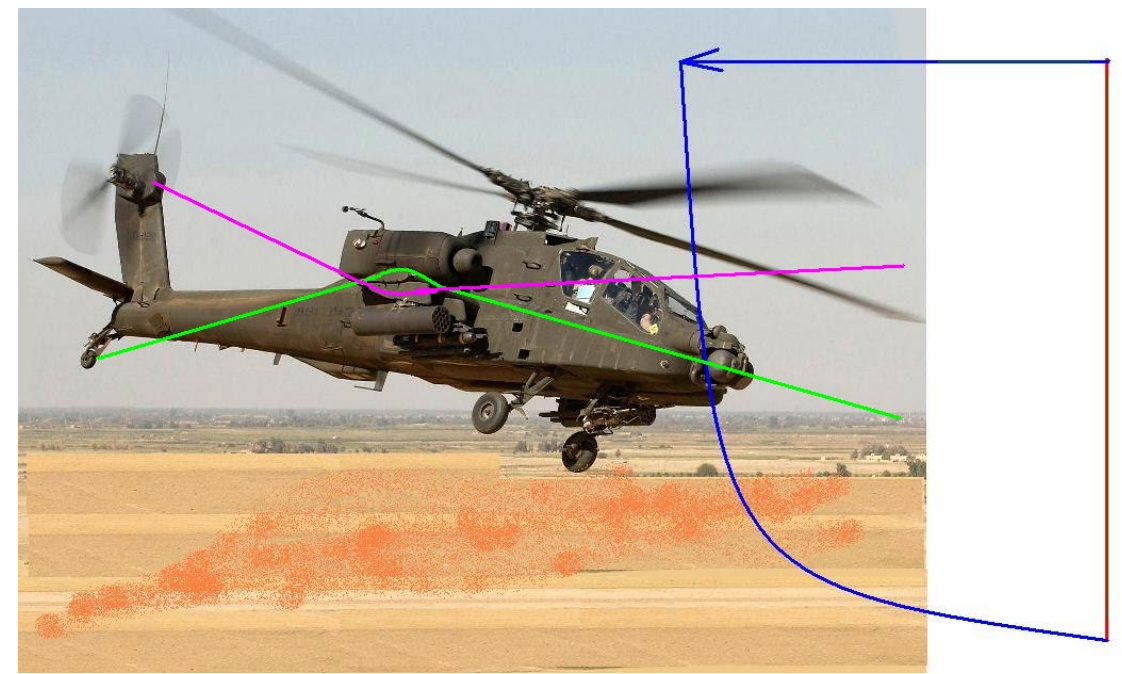

Combat helicopters frequently must operate in the part of Planetary Boundary Layer (PBL) (see Fig. 5) characterised by the presence of dust and many other aggressive agents, particularly, in desertic areas and in marine sites, so the aerodynamic performance of their ailerons reduced spanwise lenght, carrying out weapon systems, may be reduced within unacceptable values and consequent relevant risks for the stability of the copter. This seems to clash with the fact, as said, according to some experts, that aileron for weapon systems of helicopter are not involved in the global lift of the copter, but their operative function is only to carry the combat systems.

Nevertheless, for an example, the crash occurred to US combat helicopter showed in Fig. 4 suggests a different point of view, and an aileron damage, perhaps due to a kind of dynamic stall phenomenon, seems have been caused the copter fall. In the present paper, after an deep analysis about the operative running conditions of a typical combat helicopter, the results of an expirimental analysis carried out on a Water Table Test Bench are shown. The experimental analysis concerns of different aerodynamic profiles used in the above mentioned ailerons. Generally, NACA 0012 or 0018 airfoils are employed to realise the cross section of wartime loads ailerons. But these profiles have low lift coefficient and reduced value of aerodynamic efficiency and are symmetrical ones. During the evolutions in combat 
actions, the aileron may experience lift and inverse lift with corresponding general lift decrease or at least a relevant unbalance in the global lift, hazardously oscillating. These problems could be avoided using FFA-W1-128 or 182 airfoils, profiles belonging to FFA-W1-xxx serie [3].

\section{Some Aspects of Helicopter Aerodynamics}

During operative actions, the modern combat helicopters experiment different lift conditions with severe and rapid change of balance and orienting and position as shown in Figs. 6 and 7 [14]. In the Figs. 5, 6 and 7 are summarised some aspects of helicopter aerodynamics as: wake, manoeuvreing motion (hovering, trimming and yawing pr lateral oscillating) and so on ([6], [10], [13] and [14]).

\section{FIGURE 5.}

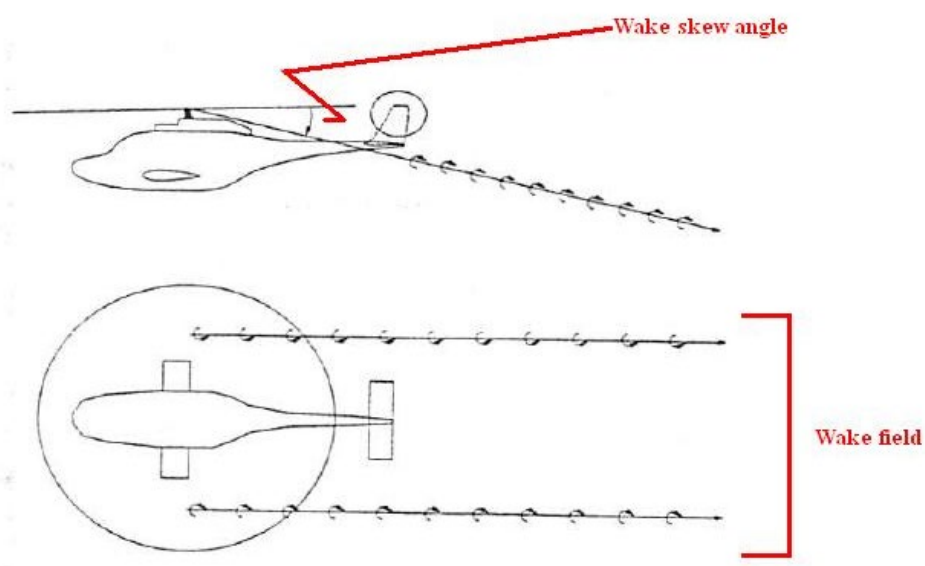

FIGURE 6. ( $T$ as thrust, $M$ as moment and $V$ as speed)

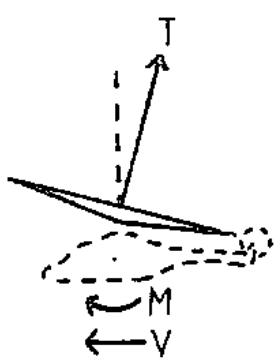

(a)

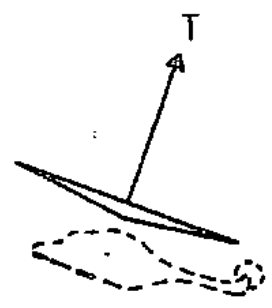

(b)

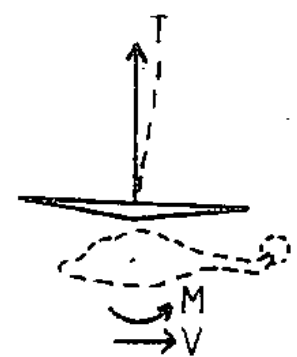

(c)

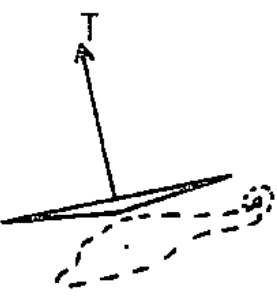

(d)

Longitudinal dynamic instability in hover. 
FIGURE 7. (L as Lift and $w_{\infty}$ undisturbed speed)
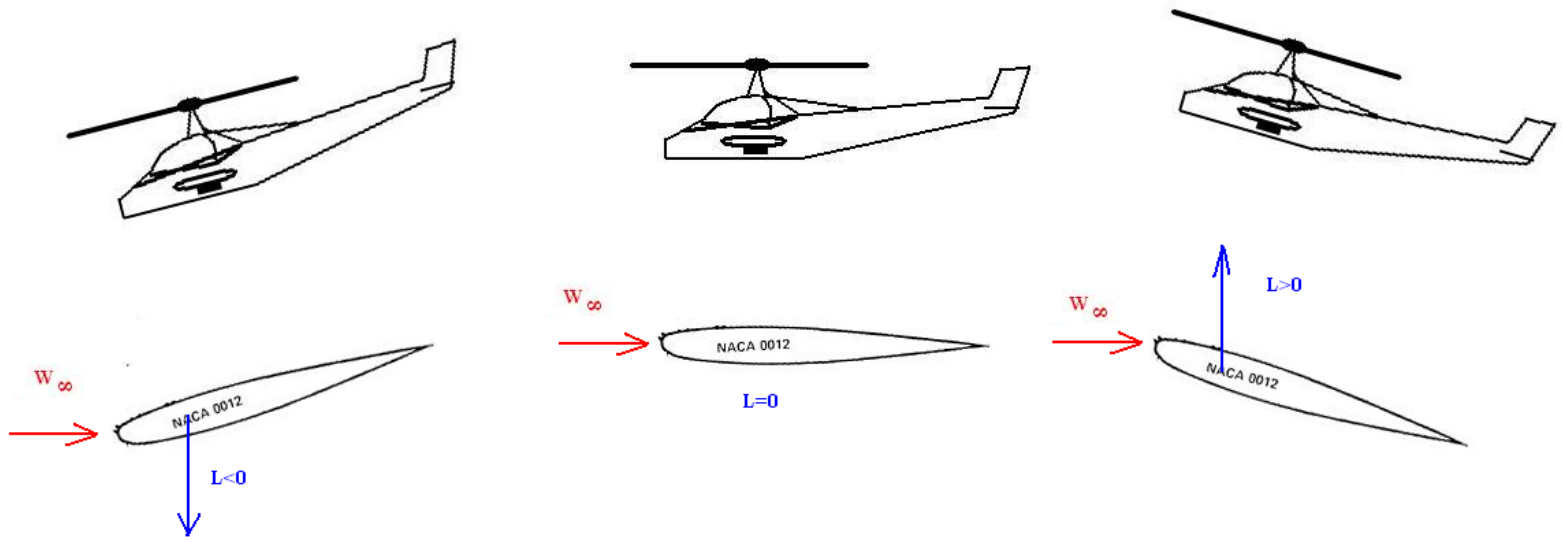

In Fig. 8 the system of aerodynamic forces acting on an airfoil and the referring system of an oscillating or pitching airfoil are shown.

\section{FIGURE 8.}

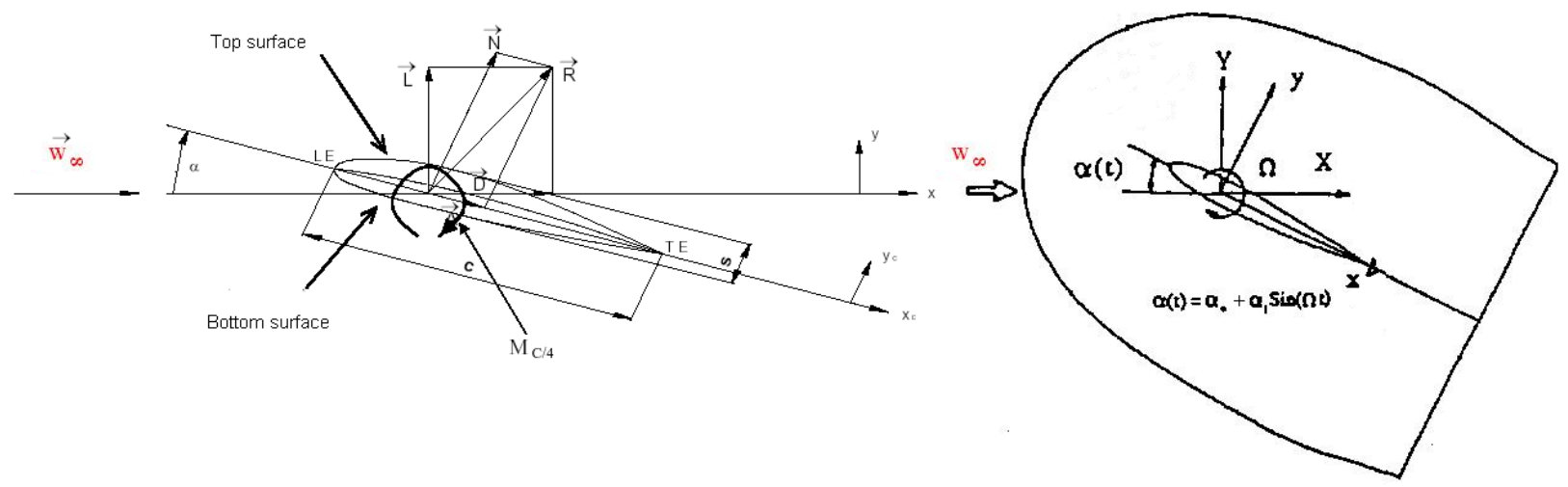

The (1) equation (related to Fig. 8) shows the characteristics of oscillating motion, where $\alpha$ is the incidence angle or attack angle, and $\Omega$ or $\omega$ the pulsation of pitching motion, while $\mathrm{L}$ is the lift, $\mathrm{D}$ the drag ( $\mathrm{N}$ and $\mathrm{R}$ are the components of the thrust), $\mathrm{M}$ the pitching moment and $\mathrm{w}_{\infty}$.

The (2) equation shows the reduced frequency $\mathrm{K}_{\mathrm{c}}$, where $\omega$ is the pulsation of pitching motion $\mathbf{c}$ the chord airfoil length and $\mathbf{w}_{\infty}$ the freestream velocity $(\mathrm{m} / \mathrm{s})$ :

$$
\begin{gathered}
\alpha(\mathrm{t})=\alpha_{0}+/-\alpha_{1} \sin (\Omega \mathrm{t}) \\
\mathrm{K}_{\mathrm{c}}=\omega \mathrm{c} / 2 \mathrm{w}_{\infty}
\end{gathered}
$$

As shown in the Fig. 7, in three different position of the yawing-copter, the lift of aileron carrying weaponry loads may change from direct to inverse in a short time, with different effects on stability of the helicopter and its lift.

In the Fig. 9 the streamlines around the above mentioned ailerons are shown, and similarly in Fig. 10 where in COMSOL's way the same streamlines have been showed. 


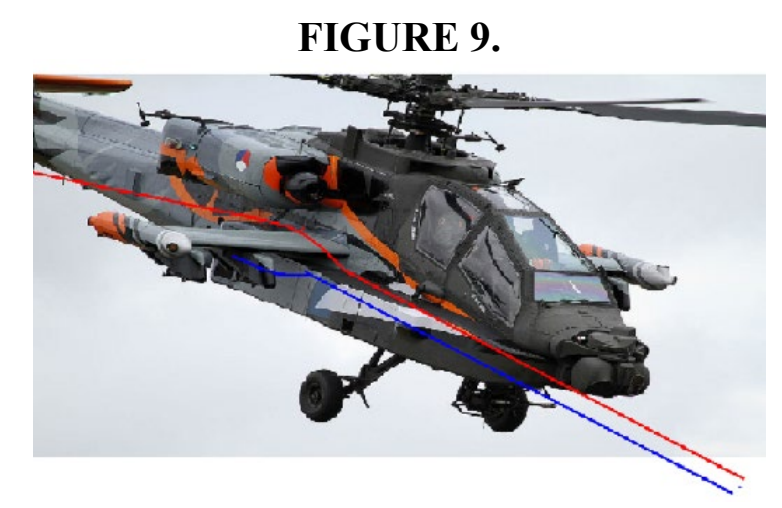

FIGURE 10.
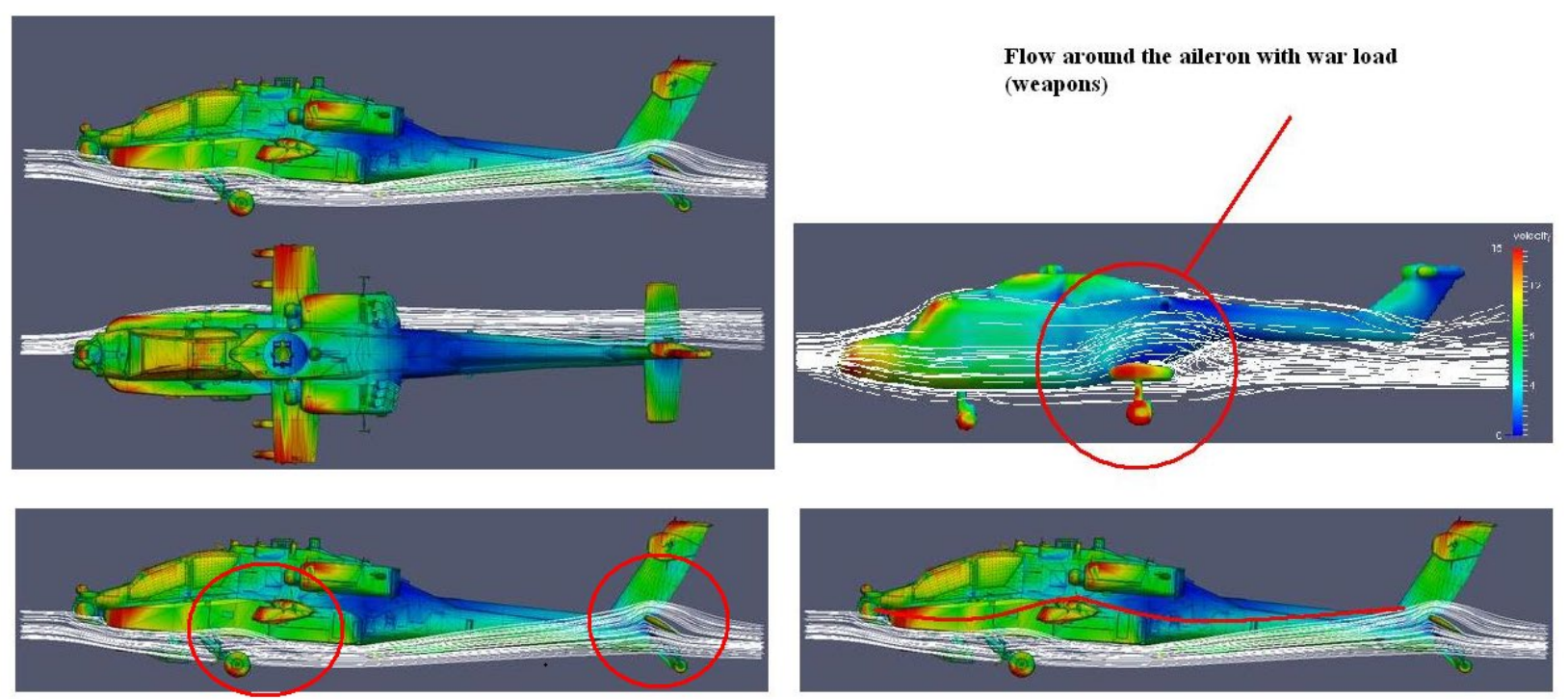

As shown in Fig. 10, the ailerons carrying weapons seem to have an interesting contribution to the helicopter global lift. The visualizations shown in Fig. 10 are a COMSOL elaboration of the analysis carried out in [9].

\section{Airfoils data and characteristics}

The aileron airfoils used have a typical section as NACA 0012 or 0018 whose lift characteristics are shown in Fig. 11 (taken from [1]).

NACA 0012 airfoil is symmetric one and it is characterised by a t/c (thickness/chord length) ratio 12\%. At Re value ranging about 1-9 million, it shows a maximum lift coefficient value ranging 1.0-1.5 at an attack angle about $10^{\circ}-14^{\circ}$. It shows a wide sensitivity to roughness ad fouling increase.

The FIGURE 12 shows the results of an experimental analysis carried out on Water Table Test Bench by [5] under fouling and roughness increase conditions with solid particles deposition and adhesion on the upper surface of airfoil, resulting, particularly, in a modified geometry at the Leading Edge (LE). 
FIGURE 11.

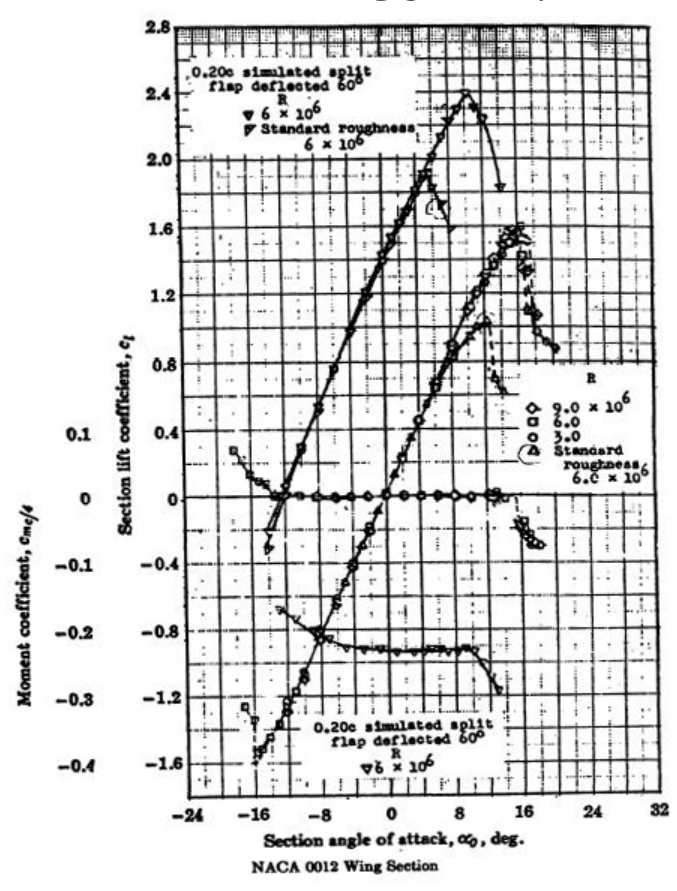

FIGURE 12.

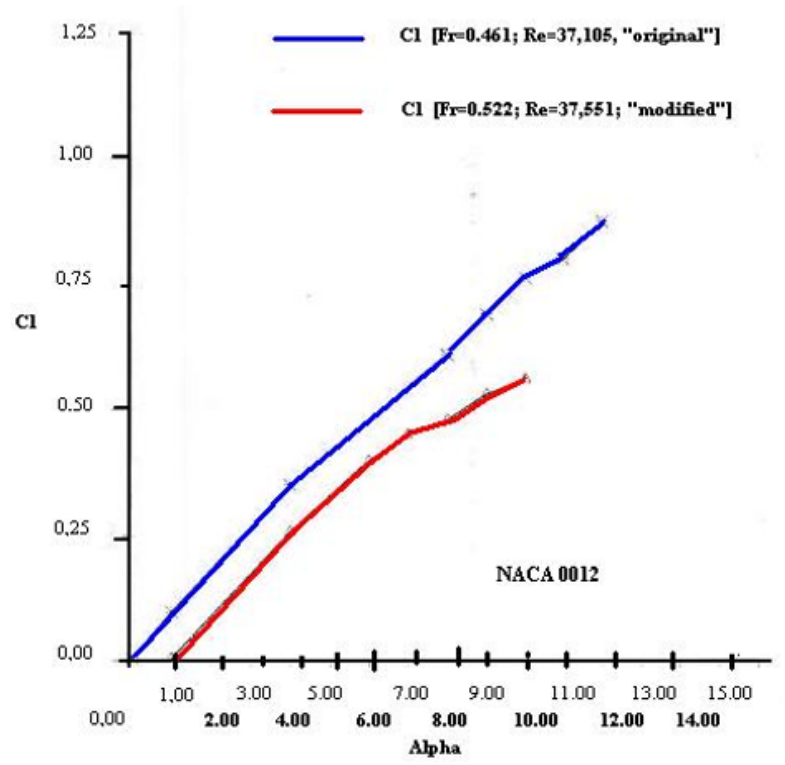

The Figs. 13 and 14 show the aspect and data about FFA-W1-182 airfoil from [3].

FIGURE 13. 
FIGURE 14.

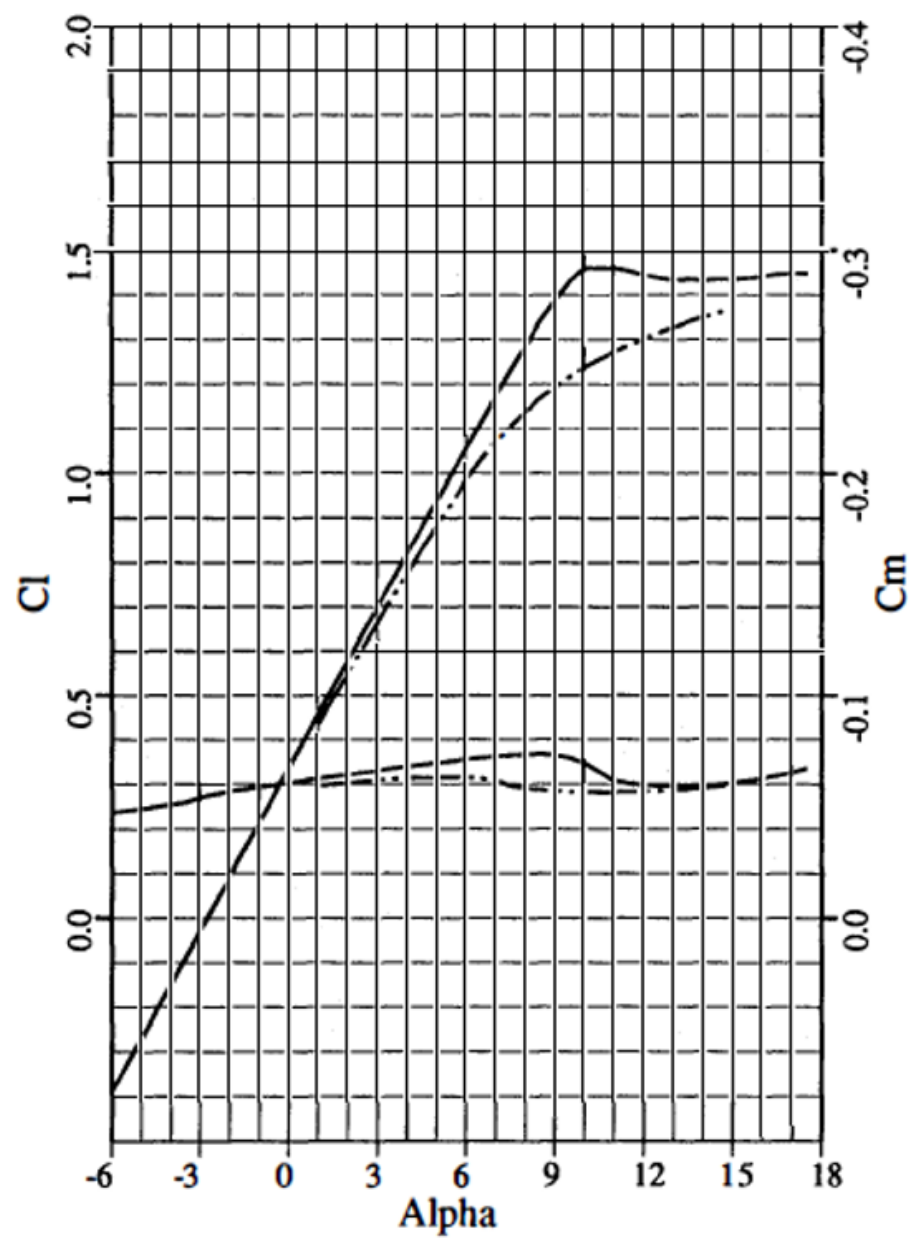

The FFA-W1-xxx serie is characterised by asymmetry, double curvature of meanline and upper and lower surface. The serie experiments BL transition and separation control, high value in $\mathrm{C}_{\mathrm{Lmax}}$ and in aerodymanical efficiency ([3] and [5]).

As above described, during the pitching motion, as consequence of helicopter motion during search or combat action, an aileron may experiment severe and rapid change in lift value with consequent possible cycle, resulting in a kind of dynamic stall as suggested by [6] and [11].

Another fact may be very important, as zero-lift angle may influence the pitching moment [1], every variation in pitching moment may be investigated [4].

\section{Test Equipment}

The profiles, which were reproduced in similitude and on a reduced scale, were tested using Lamb's Hydraulic Analogy on the Water Table Test Bench at the Dipartimento di Ingegneria Meccanica ed Aerospaziale' at "La Sapienza" University of Rome. They were tested in isolated configuration, fixed or oscillating around a point at the chord quarter, driven by a step-by-step electric motor. As known, the rules shown in Table 1 below are valid for the Analogy. As known, in the Hydraulic Analogy, the Reynolds number $(\mathrm{Re})$ cannot be reproduced in the same way as the Mach number, that is equal to the 
Froude number. However, on the basis of an important contribution by [12] it has been shown through experiments that the efflux in the air and on the Water Table behave in the same way even if the Re numbers are different. The tests, as established by [7], were carried out within the Re range in which the Strouhal number is kept independent from Re's variation, with the undoubted benefit of being able to take advantage of the lengthening of non-stationary phenomena made possible by the Analogy. In Lamb's Analogy, the exponent $\mathrm{k}$ of the adiabatic process is equal to 2 and not to 1.4 , thus, by approximating the efflux in the air with that in the "hydraulic gas" an error is introduced which increases with the Ma number. This error is between $4.5 \%$ for $\mathrm{Ma}=\mathrm{Fr}=0.4$ and $13.3 \%$ approximately, where $\mathrm{Ma}=\mathrm{Fr}=0.5$ as shown in Fig. 15 .

Specific corrections have been taken into account such that the chord, for some attack angles, becomes of the same order of magnitude as the flow free section.

TABLE 1. Characteristic parameters of Lamb's Analogy

\begin{tabular}{|c|c|}
\hline Gas flow & Water flow \\
\hline Pressure Wave Speed: $\mathrm{c}=(\mathrm{KRT}) \sim 0,5$ & Gravity Long Wave Speed: $\mathrm{a}=(\mathrm{gh}) \sim 0,5$ \\
\hline Mach Number: $\mathrm{Ma}=\mathrm{u} / \mathrm{c}$ & Froude Number: $\left.\mathrm{Fr}=\mathrm{w} / \mathrm{a}=\mathrm{u} /(\mathrm{gH})^{\wedge} 0,5\right)$ \\
\hline Density ratio: $\rho / \rho 0$ & Water Heights Ratio: $\mathrm{h} / \mathrm{h} 0$ \\
\hline Pressure coefficiente ratio: $\mathrm{p} / \mathrm{p} 0$ & Water Heights Squared Ratio: $(\mathrm{h} / \mathrm{h} 0)^{\wedge} 2$ \\
\hline Temperature Ratio: $\mathrm{T} / \mathrm{T} 0$ & Water Heights Ratio: $\mathrm{h} / \mathrm{h} 0$ \\
\hline
\end{tabular}

FIGURE 15. Diagram showing the evaluation of error using the Analogy.

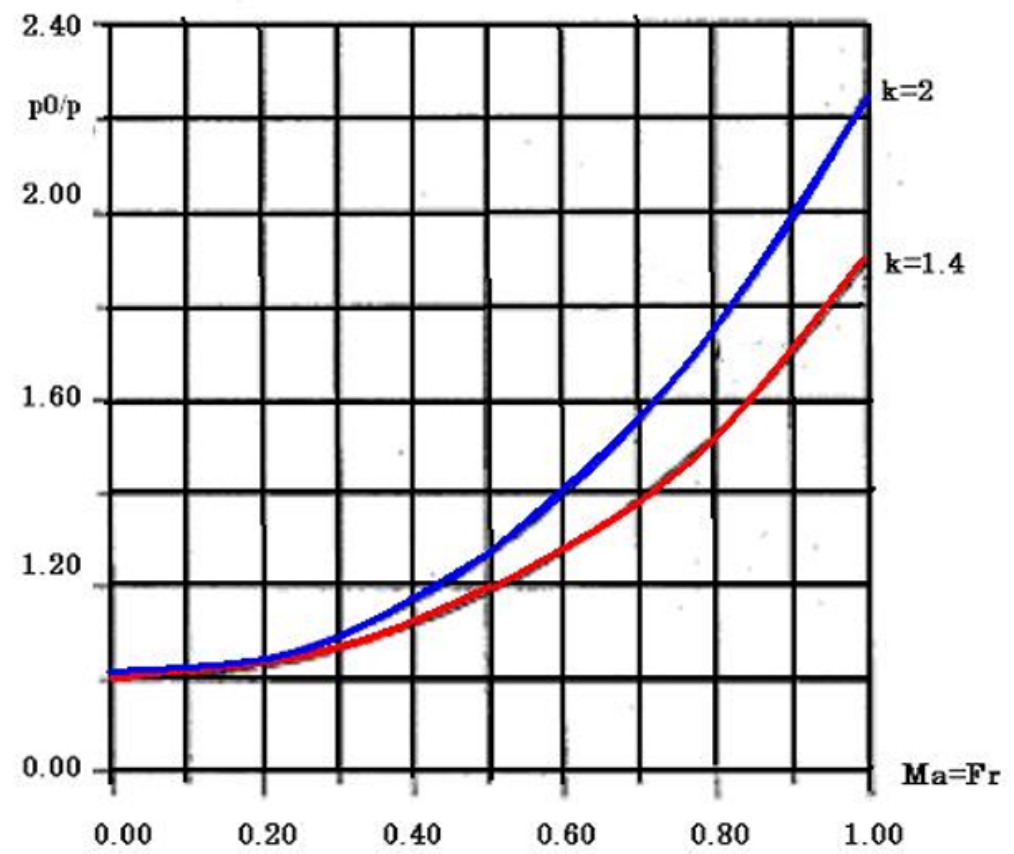

The above mentioned corrections are provided (in terms of the lift coefficient $\mathrm{c}_{\mathrm{L}}$ ), with reference to the chord $\mathrm{c}$ and length of the test section h, from: 


$$
\Delta c_{L}=c_{L} \cdot\left[-\frac{\pi^{2}}{48} \cdot\left(\frac{c}{h}\right)^{2}+\frac{7 \cdot \pi^{4}}{3072} \cdot\left(\frac{c}{h}\right)^{4}\right]
$$

\section{Tests Carried Out}

Essentially two types of tests were carried out on the isolated profile in static and pitching motion characterised by a $\mathbf{K}_{\mathbf{c}}$ value ranging between 0.02 and 0.075 . In every case, tests were then carried out both on profiles in the original conditions and with varied characteristics due to fouling or particles deposition and adhesion and then, finally, in pitching motion conditions between $-15^{\circ}$ and $15^{\circ}$ even in similitude conditions. Test outlines are shown in Figs. 12, 16 and 17, while the following typical equation was used to calculate the lift coefficient:

$$
c_{L}=\frac{\cos \alpha}{2 \cdot F r^{2} \cdot h_{\infty}^{2} \cdot l} \cdot \sum_{i}\left[\left(h_{i}^{2}+h_{i+1}^{2}\right)_{\text {sup }}-\left(h_{i}^{2}+h_{i+1}^{2}\right)_{\text {inf }}\right] \cdot X_{i}
$$

where $\mathbf{l}$ is the chord length, $\boldsymbol{\alpha}$ the angle of incidence (or attack), $\mathbf{h}$ the height at the sides of the profile and $\mathbf{X}_{\mathbf{i}}$ the points of measurement along the chord.

The conditions of dynamic stall are a consequence of the pitching motion shown by equations (1) and (2), and the most interesting results are related to the case of $\mathrm{K}_{\mathrm{c}}=0.075$.

FIGURE 16. Comparison about airfoil FFA-W1-182 in original and modified version

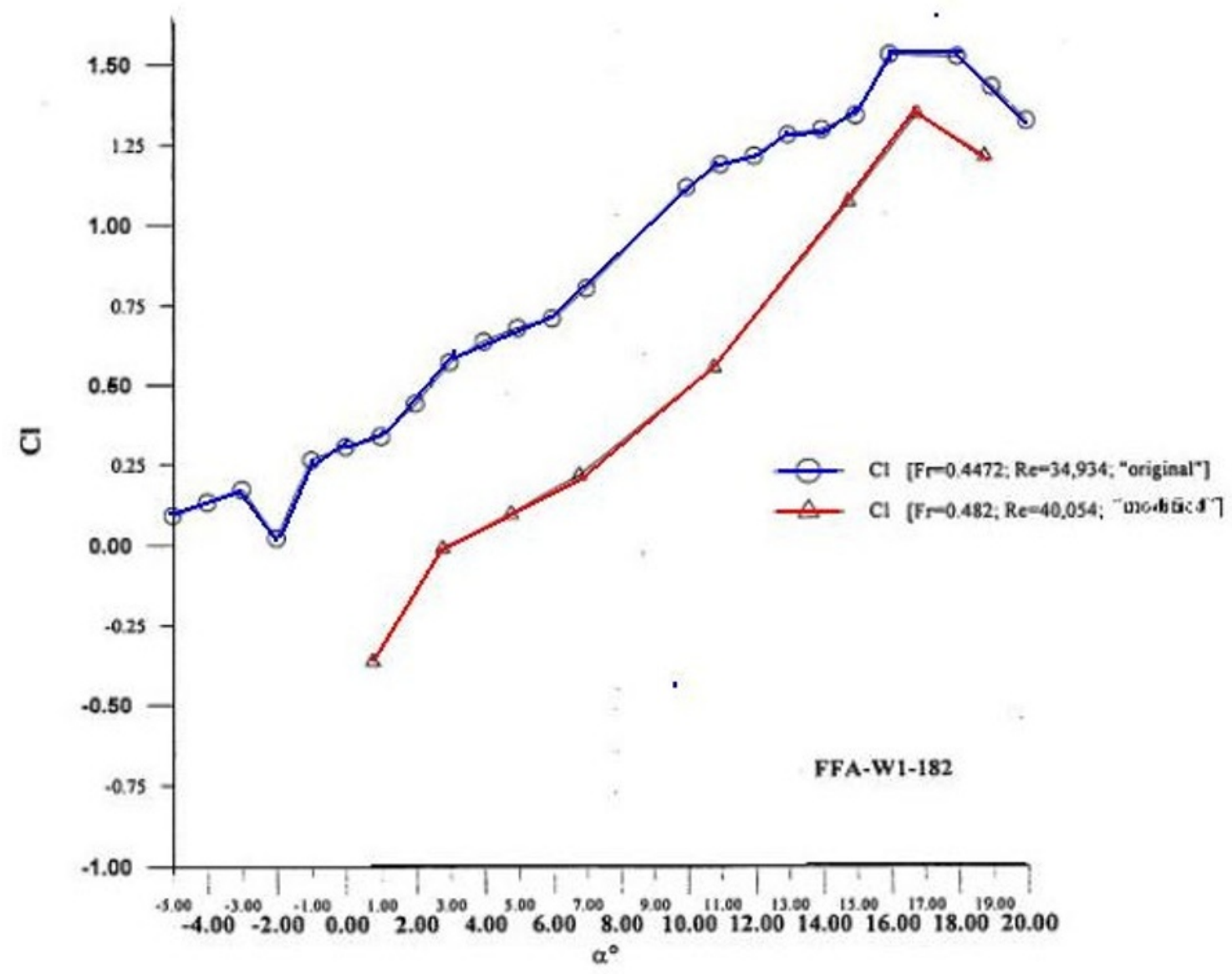


FIGURE 17. Comparison of airfoil NACA0012 and FFA-W1-182 under dynamic stall conditions
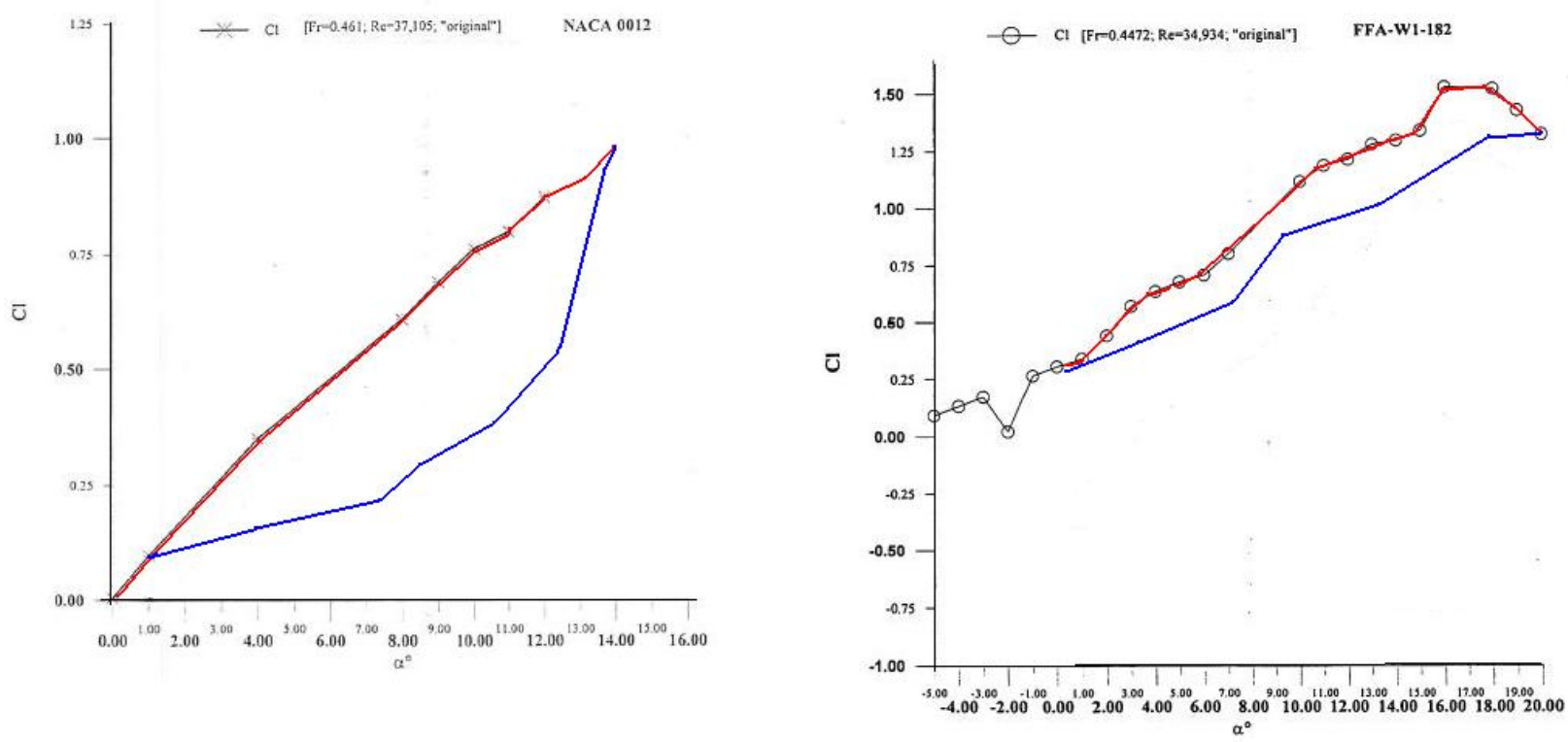

As final analysis, the Figs. 18 and 19 report about the false colours analysis carried out applying a false colours procedure, introduced by the Author. This analysis shows the structure of the flow over lower and upper surface during the pitching motion of NACA 0012 (Fig. 18) and FFA-W1-182 (Fig. 19). This procedure is confirmed as very useful in underlining flow structures over airfoil surfaces.

\section{FIGURE 18.}
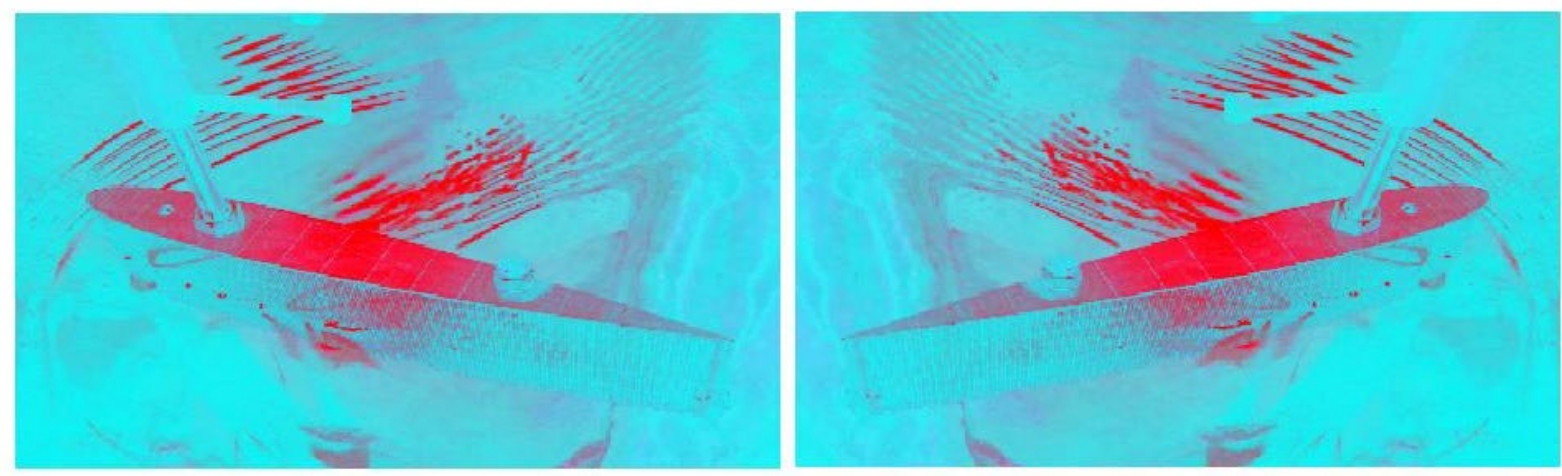

FIGURE 19.
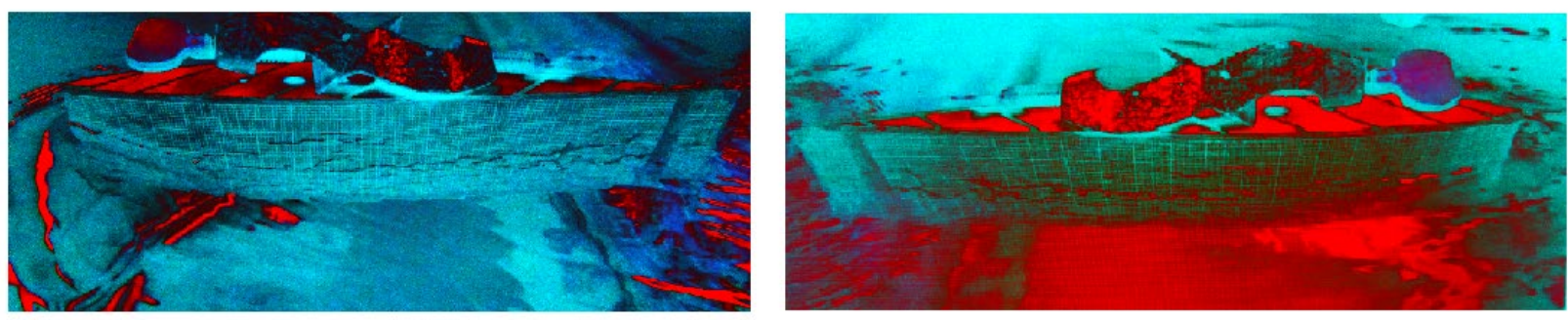

\section{Conclusions}

The tests carried out were of two different kinds: static tests in original and modified geometry of the airfoil, and dynamic ones in pitching motion (only in original geometry) characterised by oscillation 
ranging values of $\alpha+/-15^{\circ}$, reduced frequency $\mathrm{K}_{\mathrm{c}}=0.02-0.075, \mathrm{Ma}=\mathrm{Fr}=0.4-0.65, \mathrm{Re}=60.000$ (corresponding in the Analogy vision by [12] to 3-6 millions [1]).

The static tests concerning of NACA0012 airfoil have shown (Fig. 12), in "modified" geometry:

a) a reduction in $\mathrm{C}_{\mathrm{Lmax}}$ value;

b) the increase of angle of zero lift, while the slope of lift curve is unchanged.

The same airfoil in dynamic tests has shown (Fig. 17): the slope of the lift curve and its maximum value are unchanged, while a wide cycle area due to dynamic stall does exist. These results seem to be according to [11].

For the FFA-W1-182 airfoil we have observed, in static tests and in "modified" geometry (Fig. 16):

a) a lower reduction in in $C_{L m a x}$ value;

b) an unchanged value of zero-lift angle and the same lift curve slope;

while, in dynamic tests (Fig. 17), the slope and the maximum value of lift curve are unchanged and the dynamic stall is characterised by a narrow area cycle. The global measuring chain uncertainty is in the range of $2-3 \%$ as a consequence of the system analysis and procedure (using an optical system in observation and recording).

These preliminary results may be very important because of FFA-W1 serie, if used in the above mentioned ailerons, might have a reduced sensitivity to pitching moment variations and to dangerous effects of lift change during manoeuvring motions. The Figs. 18 and 19 show the FFA-W1-182 has a more controlled transition and separation in BL. During some tests, freestream irregularities have been observed: they are due to circulating pump disturbances induced in the flow, nevertheless their influence on the results was only about $0.5-1.0 \%$. The possible error due to the difference exposed in Fig. 15 was less $2.0 \%$.

Successive tests are carrying out to analyse in a better way some aspects of the question, particularly, about the characteristic of the dynamic stall of NACA0012, 0018 and FFA-W1-xxx serie.

\section{Acknowledgments}

The Author would like to thank Prof. GianPaolo Romano for many given suggestions, and a special thank to the friend and colleague Prof. Alessandro Corsini for his availability.

\section{References}

[1] Abbott, I. H. - von Doehnoff, A. E. (1959): Theory of Wing Sections - including a Summary of Airfoil data, New York, Dover Publications Inc., pp. ;

[2] Amura, M. et Al. (2014): Failure of an helicopter main rotor blade, Procedia Materials Science 3, pp. 726-731;

[3] Björck, A. (1990): Coordinates and Calculations for The FFA-W1-xxx, FFA-W2-xxx ad FFA-W3xxx Series of Airfoil for HAWT, FFA TN 1990-15, pp. 239; 
[4] Chandrasekhara, M. S. et Al. (1990): Compressibility effects on dynamic stall of oscillating Airfoils, Final Report U.S. Army Research Office 23394-EG, pp. 43;

[5] De Pratti, G.M. et Al. (2003): (2003): "Performance decay analysis of new rotor blade profiles for wind turbine operating in offshore environment", in Wind Engineering, vol. 27, $\mathrm{n}^{\circ}$ 5, pp. 371-379;

[6] Dindar, M. et Al. (1993): "Nonequilibrium Turbulence Modeling Study on Light Dynamic Stall of a NACA0012 Airfoil", in J. of Aircraft, vol. 30, N 3, May-June. 1993, pp.305-308;

[7] Ericsson, L. E. (1980): "Karman Vortex Shedding and the effect of body motion", in AIAA Journal, Article $\mathrm{n}^{\circ}$ 79-1531R, vol. 18, n 8, aug. '80, pp. 935-944;

[8] Ferguson, K. - Thomson, D. (2016): Maneuverability Assessment o a compound helicopter configuration, J. Am. Helicopter Soc. 61, 1-15;

[9] Kyusumov, A.N. et Al. (2013): Simulation of Flow around Isolated Helicopter Fuselage, EPJ Web of Conferences, 01103 (2013) 45, DOI: 10.1051/epjconf 201/34501103, pp. 7;

[10] Mattioli, E. (1988): Aerodinamica, Torino, Levrotto \& Bella Ed., pp. 535;

[11] McAlister, K.W. (1978): Dynamic Stall Experiments on The NACA0012 Airfoil, MASA Tech. Paper 1100, pp. 170:

[12] Orlin, J. W. et Al. (1947): "Application of The Analogy between Water Flow with a Free Surface and Two-Dimensional Compressible Gas Flow”, NACA Report n 875, pp. 18;

[13] O’Rourke, M. J. (1994): "Simulation Model for Tail Rotor Failure”, in J. of Aircraft, vol. 31, № 1, Jan.-Feb. 1994, pp.197-205;

[14] Seddon, J. (1990): Basic Helicopter Aerodynamics, Oxford, BSP Professional Books, pp. 136;

[15] Stupke, S. et Al. (2012) : Measurement and Analysis of Vibrations on the Helicopter Structure in Order to Detect Defects of Operating Elements, Scentific Techicanl Review, Vol. 62, N 1, pp. 58-63;

[16] USAF (2020): Data collection about Combat and SAR-Search and Rescue Helicopter Crashes, in https://www.safety.af.mil/Divisions/Aviation-Safety-Division/Aviation-Statistics;

[17] Wu, M. - Chen, M. (2019): Non linear Modeling and Flight Validation of a Small-Scale Compound Helicopter, in Applied Science, 9, 1087; doi:10.3390/app. 9061087, pp. 21. 